\title{
Checking the accuracy of selected methods of probe radius correction
}

\author{
Sprawdzenie dokładności wybranych metod korekcji promieniowej
}

\author{
MAREK MAGDZIAK \\ MARCIN KRAWCZYK \\ ANDRZEJ KAWALEC \\ JERZY SŁADEK*
}

\author{
DOI: https://doi.org/10.17814/mechanik.2018.11.170
}

The paper concerns the analysis of accuracy of two methods of probe radius correction which are based on Bézier curves. Those methods can be applied in the case of measurements of free-form surfaces. The analysis of accuracy of selected methods was done in relation to reference corrected measured points.

KEYWORDS: coordinate measuring technique, free-form surface, probe radius correction

\section{Artykuł prezentuje analizę dokładności dwóch metod korekcji promieniowej, które bazują na krzywych Béziera. Metody te mogą być stosowane do pomiaru powierzchni swobodnych. Analiza dokładności wybranych metod została przeprowadzo- na w odniesieniu do wzorcowych skorygowanych punktów pomiarowych. \\ SŁOWA KLUCZOWE: współrzędnościowa technika pomiaro- wa, powierzchnia swobodna, korekcja promieniowa}

Coordinate measurements of products can be conducted using various coordinate measuring systems. An example of automated measuring system which can be applied in coordinate metrology is a coordinate measuring machine (CMM). It can be equipped both with contact and non-contact measuring probes $[1,2]$. Such type of measuring system is still widely used in many enterprises, e.g. in aeronautical, automotive and shipbuilding industries.

Coordinate measuring machine is very universal and due to that fact it can be used during digitalization of products at the first stage of their reverse engineering process or during the final verification of the accuracy of product manufacturing at the last stage of manufacturing process. CMM can be applied for the purpose of measuring products characterized by regular geometric shapes and having curvilinear surfaces which are frequently used in aeronautical and cosmic industries. Examples of products measured using such measuring system are the ones like bodies, gears or blades applied in aero-engines [3,4]. Measurements of such products are possible thanks to, among other things, wide opportunities of metrological software cooperating with coordinate measuring machines. In the case of the Carl Zeiss company there can be distinguished, e.g. Gear Pro or Blade Pro software packages.

The accuracy of coordinate measurements performed using a CMM depends on several factors, e.g. [5,6]: applied measurement strategy, accuracy of used coordinate measuring machine, environmental conditions tak-

\footnotetext{
* Dr inż. Marek Magdziak (marekm@prz.edu.pl), dr hab. inż. Andrzej Ka walec (ak@prz.edu.pl)-Wydział Budowy Maszyn i Lotnictwa Politechniki Rzeszowskiej; dr inż. Marcin Krawczyk (mkrawczyk@mech.pk.edu.pl), prof. dr hab. inż. Jerzy Sładek (sladek@mech.pk.edu.pl) - Laboratorium Metrologii Współrzędnościowej Politechniki Krakowskiej
}

ing place in measurement laboratory, CMM operator and measured product.

The strategy of contact coordinate measurements can consider, among other things, [5,6]: scanning velocity, number of measured points, distribution of measured points, method of defining the coordinate system of a product, setup concerning fitting measured data to nominal data, method of probe radius correction.

The mentioned factors influence the uncertainty of coordinate measurements made using coordinate measuring machines. In the paper focus is put on the accuracy of selected methods of probe radius correction used for computing coordinates of corrected measured points on the basis of indicated measured points. The corrected measured points represent real points of contact of the stylus tip of measuring probe with product's measured surface. On the other hand, the indicated points are the centres of the stylus tip of measuring probe.

The correction process requires as precise as possible information concerning the components of radius correction vectors at measured points as well as the radius of the stylus tip of measuring probe. The radius of the stylus tip is obtained during the qualification process of probing systems. The problem of accuracy of probe radius compensation is investigated in several research centres. There can be found many publications presenting new methods for computing corrected measured points. Examples of such publications are [7-10].

In the case of work [8] there are presented three methods of radius correction of the stylus tip of measuring probe including methods using linear functions and circles. In the case of linear functions the correction vector is perpendicular to the straight line passing through two indicated points. Application of circles for radius compensation consists in creating subsequent circles based on three consecutive indicated points. Direction of the radius correction vector is determined by a straight line passing through the indicated measured point and the centre of created circle.

\section{Analysed methods of probe radius correction}

In the paper there is analysed an accuracy of two methods used for probe radius compensation. Both are based on Bézier curves.

In the first case each three subsequent indicated points are interpolated with the second degree Bézier curves, while in the second case indicated measured points are interpolated with the fourth degree Bézier curves. Those fourth degree Bézier curves interpolate five subsequent indicated measured points representing the centre of the stylus tip of measuring probe. Corrected measured points are computed based on vectors tangent to the curves interpolating consecutive groups of points. Computations 
are always done for the central point of each group of points. The components of the tangent vector $\mathbf{T}_{1}$ in the case of method based on the second degree Bézier curves are computed with equation in which $\mathbf{P}_{0}, \mathbf{P}_{1}$ and $\mathbf{P}_{2}$ represent subsequently distributed indicated measured points [9]:

$$
\mathbf{T}_{1}=\frac{\left(t_{1}-1\right)^{2} \mathbf{P}_{0}+\left(2 t_{1}-1\right) \mathbf{P}_{1}-t_{1}{ }^{2} \mathbf{P}_{2}}{t_{1}\left(t_{1}-1\right)}
$$

The value of parameter $t_{1}$ is computed on the basis of mutual distances between the indicated measured points. Knowledge about tangent vectors enables computation of normal vectors. Additional information about the radius of stylus tip of measuring probe makes possible computation of coordinates of corrected measured points. On the other hand, in the case of the method based on fourth degree Bézier curves suitable equations allowing to compute coordinates of corrected measured points are presented in paper [10].

\section{Algorithm for assessment of selected methods of radius compensation}

Considered methods of computing coordinates of corrected measured points were compared with the reference method. That reference method was the method of probe radius compensation used in QUINDOS software cooperating with coordinate measuring machine PMM 12106 Leitz Messtechnik. Such measuring system belongs to the equipment of the Laboratory of Coordinate Metrology, Cracow University of Technology. That system was used for making measurements of selected free-form surfaces of products. The results of measurements were coordinates of both indicated and corrected measured points. The algorithm of computations applied for the assessment of the accuracy of selected methods of probe radius correction is presented in fig. 1 .

Indicated measured points were filtered in order to obtain four groups of points (G1-G4) which differ from each other as far as the amount of measurement data contained in particular group is concerned. Filtration was done for assessing the possibility of application of analysed correction methods in the process of coordinate measurements performed not only in the case of scanning mode of measuring probe but also in the case of single-point probing mode. Measurements done in single-point probing mode are characterized, in contrast to scanning mode, by smaller number of measurement points.

Corrected measured points computed using QUINDOS software for particular products (w1-w4) and their curves (k1-k4) were interpolated with cubic B-Splines. For that purpose suitable functions within Rhinoceros software were applied. Those functions are dedicated for modelling, among other things, free-form surfaces of products. At the following stage there were computed corrected points, based on subsequent groups of indicated measured points, using the methods which apply the second and the fourth degree Bézier curves. The last stage of performed analyses consisted in comparing computed corrected measured points with B-Spline curves representing the reference points. That comparison was done along vectors normal to B-Spline curves at proper measured points. The numbers of measured points for particular products, curves and groups of points are presented in the table.

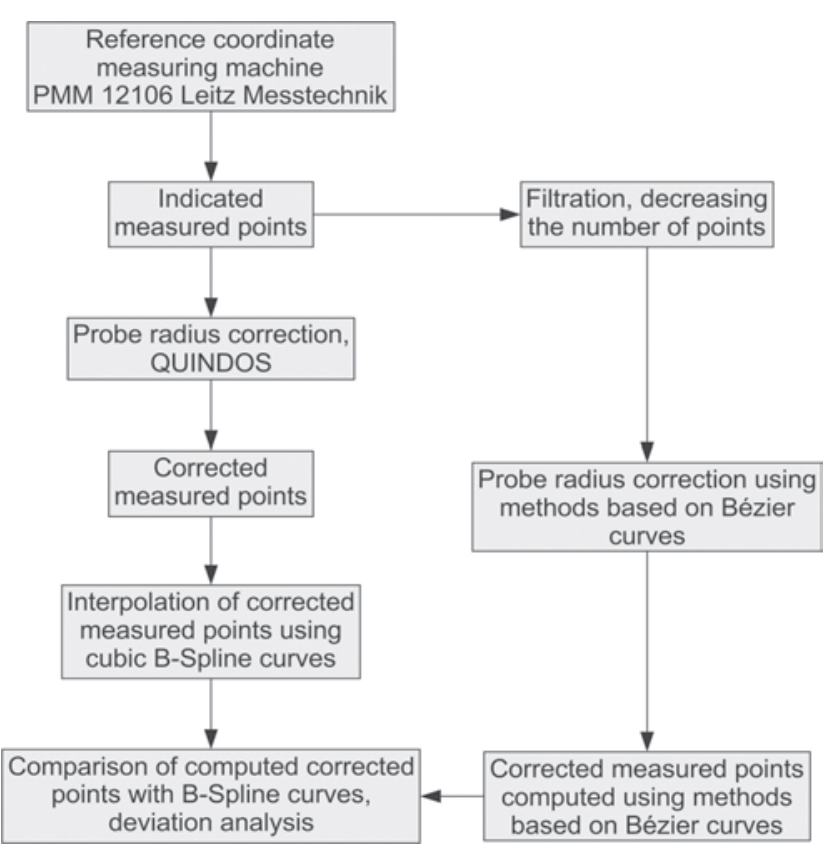

Fig. 1. Algorithm for assessment of the accuracy of two selected methods of probe radius correction

TABLE. The amount of data for considered workpieces

\begin{tabular}{|c|c|c|c|c|c|c|c|c|c|c|c|c|}
\cline { 2 - 15 } \multicolumn{1}{c|}{} & \multicolumn{4}{c|}{$w 1$} & \multicolumn{4}{c|}{$w 2$} & \multicolumn{4}{c|}{$w 3$} \\
\cline { 2 - 14 } \multicolumn{1}{c|}{} & $k 1$ & $k 2$ & $k 3$ & $k 4$ & $k 1$ & $k 2$ & $k 3$ & $k 4$ & $k 1$ & $k 2$ & $k 3$ & $k 4$ \\
\hline G1 & 212 & 195 & 194 & 203 & 213 & 211 & 210 & 204 & 198 & 194 & 189 & 187 \\
\hline G2 & 106 & 98 & 97 & 102 & 107 & 106 & 105 & 102 & 99 & 97 & 95 & 94 \\
\hline G3 & 53 & 49 & 49 & 51 & 54 & 53 & 53 & 51 & 50 & 49 & 48 & 47 \\
\hline G4 & 11 & 10 & 10 & 11 & 11 & 11 & 11 & 11 & 10 & 10 & 10 & 10 \\
\hline
\end{tabular}

\section{Measured workpieces}

Checking the accuracy of selected methods of probe radius compensation was made on the grounds of the results of measurements done in scanning mode of three workpieces consisting of four free-form surfaces with different shapes (figs. 2 and 3). All surfaces of three products were measured in one middle cross-section because the curvature of each of measured surfaces varied in only one direction.

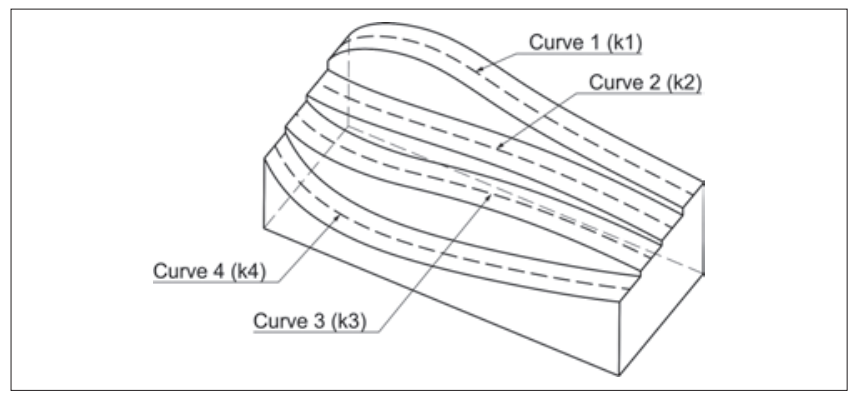

Fig. 2. The first product with measured curvilinear surfaces

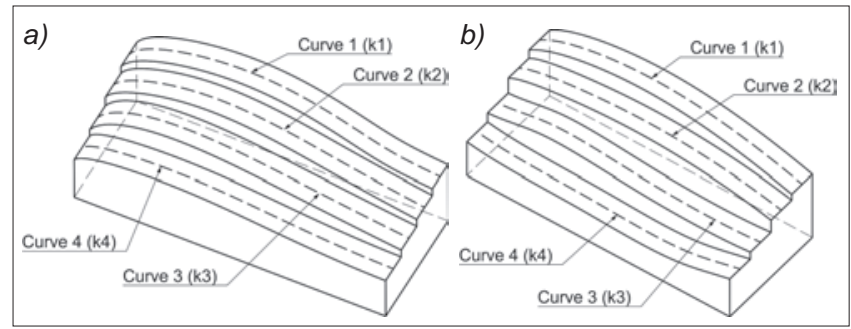

Fig. 3. The second (a) and the third $(b)$ product with measured curvilinear surfaces 


\section{Results of coordinate measurements}

Results of comparison of corrected measured points, computed using the methods based on the second and the fourth degree Bézier curves, with the B-Spline curves representing the reference points, measured with coordinate measuring machine PMM 12106 Leitz Messtechnik and QUINDOS software, are presented in figs. 4-6. Those results relate to twelve free-form surfaces which belong to the three considered products. Computations were made, in each case of measured surface, for four groups of points (G1-G4) containing different numbers of points.

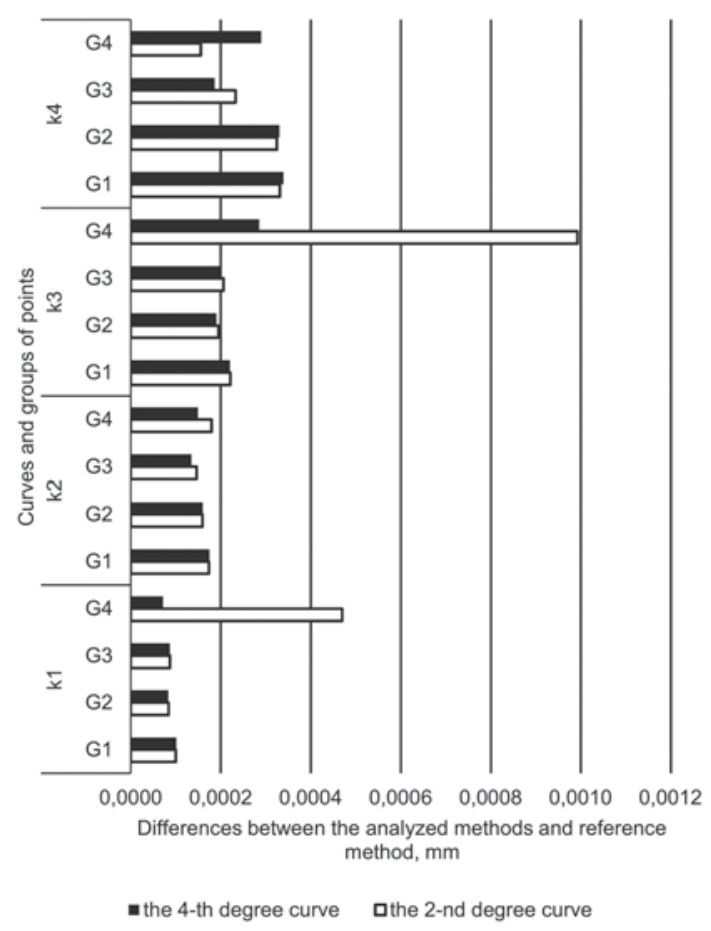

Fig. 4. Results of analyses for the first product $w 1$

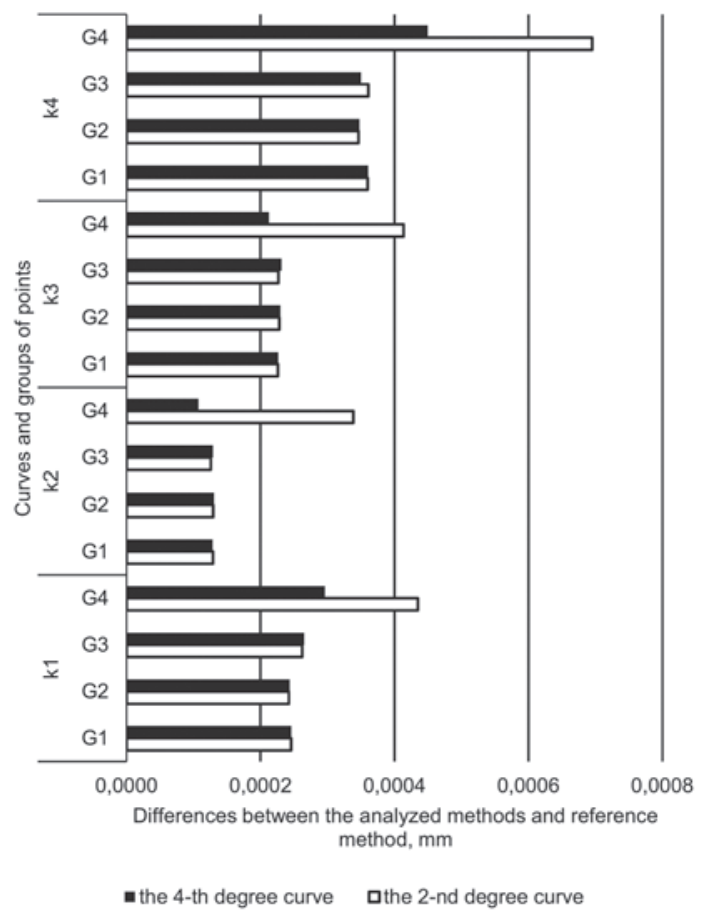

Fig. 5. Results of analyses for the second product w2

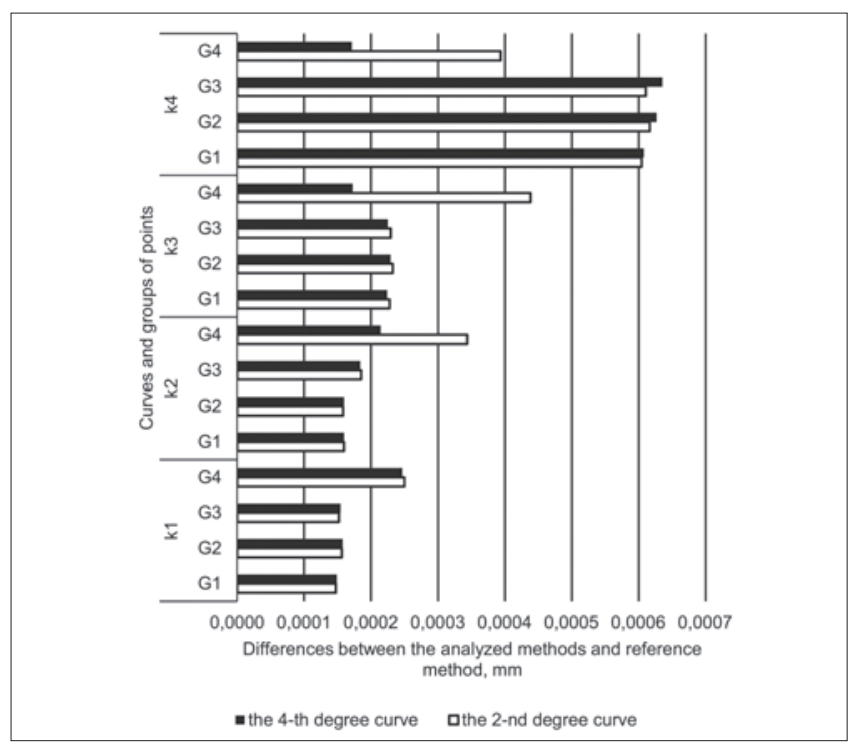

Fig. 6. Results of analyses for the third product w3

\section{Conclusions}

In most cases there were observed, on the basis of performed investigations, comparable results obtained using the two selected methods of probe radius correction. In the case of most considered curves significant differences between the computed corrected measured points and reference curves were obtained only for the G4 groups of measured points with the smallest number of points. For that sets of points in most cases better results were obtained using the method based on the fourth degree Bézier curves.

Obtained results of measurements qualify analysed methods of probe radius correction to contact coordinate measurements realized using, e.g. CMM. Calculated differences between corrected points computed using the methods based on Bézier curves and curves representing reference points do not exceed $1 \mu \mathrm{m}$. In the case of measurements conducted using CMM working in single-point probing mode and analysed methods of correction it is necessary, in order to obtain accurate results, to pay attention to proper selection of the number of measured points.

\section{REFERENCES}

1. Liu H., Wang Y., Huang X., Xue L. "Isoplanar-based adaptive sampling for model-unknown sculptured surface coordinate metrology using non-contact probe". The International Journal of Advanced Manufacturing Technology. 64, 9-12 (2013): pp. 1695-1707.

2. Sładek J.A. "Coordinate Metrology. Accuracy of Systems and Measurements". Berlin: Springer-Verlag Berlin Heidelberg, 2016.

3. Rui-song J., Wen-hu W., Ding-hua Z., Zeng-qiang W. "A practical sampling method for profile measurement of complex blades". Measurement. 81, (2016): pp. 57-65.

4. Gao C.H., Cheng K., Webb D. "Investigation on sampling size optimisation in gear tooth surface measurement using a CMM". The International Journal of Advanced Manufacturing Technology. 24, 7-8 (2004): pp. 599-606.

5. Magdziak M. "The influence of a number of points on results of measurements of a turbine blade". Aircraft Engineering and Aerospace Technology. 89, 6 (2017): pp. 953-959.

6. Carl Zeiss Industrielle Messtechnik $\mathrm{GmbH}$. "Sharing Experiences". Innovation. 18 (2015): pp. 18-21.

7. Woźniak A., Mayer J.R.R., Bałaziński M. "Stylus tip envelop method: corrected measured point determination in high definition coordinate metrology". The International Journal of Advanced Manufacturing Technology. 42, 5-6 (2009): pp. 505-514.

8. Juras B. „Metoda pomiaru zarysu o zmiennej krzywiźnie na wielowspółrzędnościowej maszynie pomiarowej”. Kraków, Poland: PhD thesis, Faculty of Mechanical Engineering, Cracow University of Technology, 1996.

9. Kawalec A., Magdziak M. "Local methods for computing offset curves". Pomiary Automatyka Kontrola. 58, 1 (2012): pp. 130-132.

10. Kawalec A., Magdziak M. "The selection of radius correction method in the case of coordinate measurements applicable for turbine blades". Precision Engineering. 49, (2017): pp. 243-252. 